\title{
Review
}

\section{An Alternative Approach to Atopic Dermatitis: Part II-Summary of Cases and Discussion}

\author{
Hiromi Kobayashi ${ }^{1}$, Kuniaki Takahashi ${ }^{2}$, Nobuyuki Mizuno', Haruo Kutsuna' and \\ Masamitsu Ishii ${ }^{1}$
}

\author{
${ }^{1}$ Department of Dermatology, Osaka City University Graduate School of Medicine, Osaka and ${ }^{2}$ Takahashi \\ Dermatology Clinic, Daito City, Osaka, Japan
}

\begin{abstract}
In the first part of this Review, we presented case-series where Kampo treatment was introduced for those atopic dermatitis (AD) patients who had failed with conventional therapy, in an attempt to prove that there exists a definite subgroup of AD patients for whom Kampo treatment is effective. In this second part, we will first provide the summary of the results for 140 AD patients we treated in 2000. The results suggest that Kampo treatment is effective for more than half of AD patients who fail with conventional therapy. In the Discussion, we will examine the evidential basis for conventional AD therapy and discuss how Kampo treatment should be integrated into the guidelines for AD therapy. We contend that Kampo treatment should be tried before systematic immunosuppressive agents are considered. As each Kampo treatment is highly individualized, it should be regarded more as 'art' than technology, and special care should be taken to assess its efficacy in clinical trial.
\end{abstract}

Keywords: Kampo medicine - atopic dermatitis-eczema - diet - herbal medicine - herbal therapy

\section{Summary of Cases}

\section{Subjects}

Of patients with intractable atopic dermatitis (AD) who visited the outpatient clinic of our hospital between January and December 2000, 140 patients who consented to have photographs taken were selected as the subjects of this summary. All patients met the criteria of AD proposed by Hanifin and Rajka (1).

\section{Treatment (Fig. 1)}

It was first confirmed that conventional Western medical therapy alone did not remit the symptoms.

Dietary change (Table 1) was recommended and introduced on patient's consent. When dietary instruction alone did not heal the symptoms, Kampo remedy was added. This principle

For reprints and all correspondence: Hiromi Kobayashi, Osaka City

University Graduate School of Medicine, Asahi-machi 1-4-3, Abeno-ku,

Osaka 545-8585, Japan. E-mail: hiromik@med.osaka-cu.ac.jp

Part I of this article appeared in Evidence-based Complementary and Alternative Medicine Vol. 1 No. 1. (eCAM 2004;1:49-62 neh015) was explained to the patients, and when consent was obtained, the procedure was started.

Herbal remedy was selected based on the pathological state and recorded. General hematology test, blood chemistry and urinalysis were performed as far as possible to investigate the presence or absence of adverse drug reactions.

\section{Evaluation}

There is still no evaluation system of the symptoms of $\mathrm{AD}$ which has gained international acceptance, although several scoring systems such as the scoring methods introduced by Costa et al. (2), SCORAD (3) and SASSAD (4) have been proposed for Western patients. We are not convinced that these can be directly applied to Asian AD patients. Therefore, we used in this series a criterion based upon the one proposed by the National Research Group on AD of Japan (5) (Table 2). In our criteria, the gravity of the disease is classified into four grades (5-7) and the decreasing points from 4 to 0 are given to these four grades ranging from the very severe to normal: very severe $=4$, severe $=3$, moderate $=2$, mild $=1$, normal (with no skin lesions $)=0$. The values before the initiation of therapy and after $\geq 6$ months were compared, and the degree of

The online version of this article has been published under an open access model. Users are entitled to use, reproduce, disseminate, or display the open access version of this article provided that: the original authorship is properly and fully attributed; the Journal and Oxford University Press are attributed as the original place of publication with the correct citation details given; if an article is subsequently reproduced or disseminated not in its entirety but only in part or as a derivative work this must be clearly indicated. 


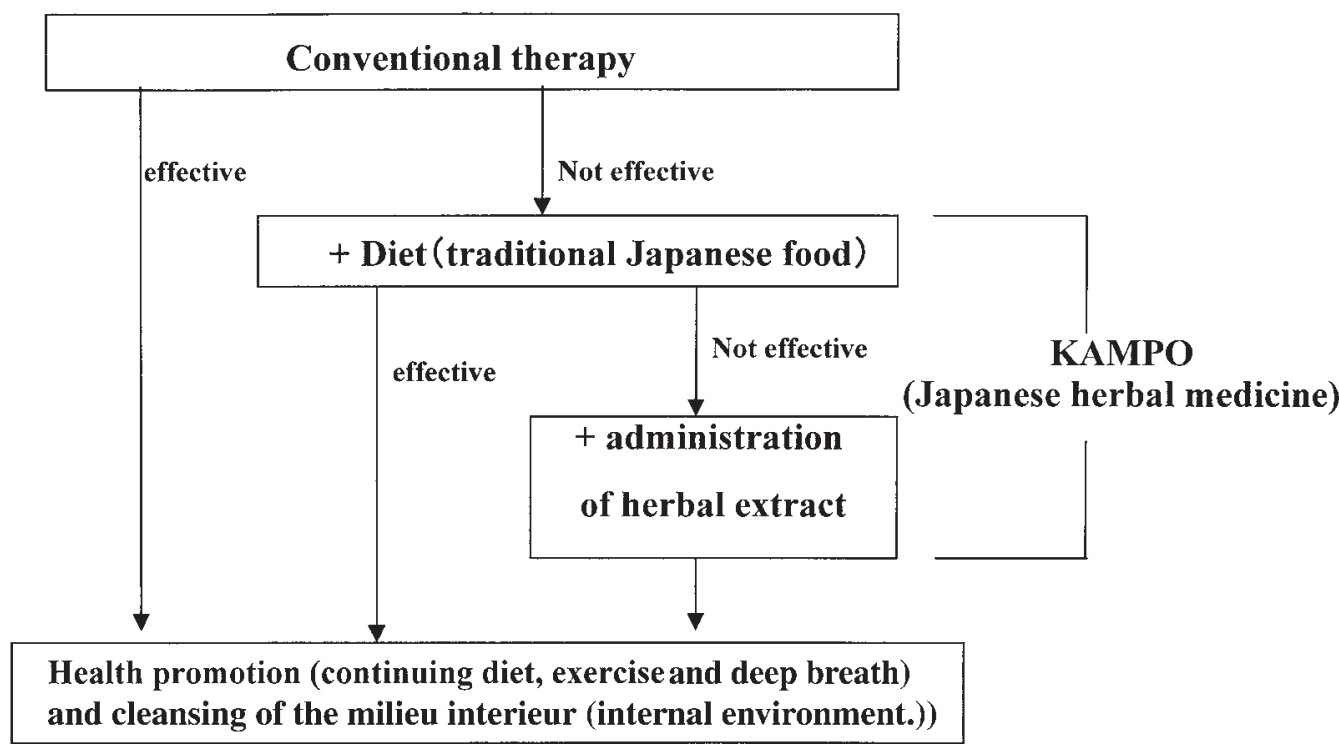

Figure 1. Methods.

Table 1. Diet instruction

1. The principle food is rice. Boiled rice is recommended for breakfast. Low-polished rice from which influence of contamination is eliminated as far as possible.

2. For dishes other than the principle food, vegetables in season, fish and shellfish/seaweed, soybean products.

3. Be careful not to ingest excess sweets, alcohol, coffee or juice.

4. Be careful not to ingest excess meats, fats or fatty oils (n-6 fatty acids in particular).

5. Avoid processed food and additives.

6. Bland taste and homemade dishes are recommended.

7. Moderation in eating and pleasant meals with sufficient chewing.

Table 2. Classification of global clinical severity proposed by the National Research Group on AD of Japan

Mild $\quad$ Only mild skin symptoms (slight erythema, dryness, scaling) regardless of the affected area

Moderate With severe inflammatory lesions (erythema, papules, erosions, infiltration, lichenification) over less than $10 \%$ of the body surface area

Severe With severe inflammatory lesions over $10-30 \%$ of the body surface area.

Very severe With severe inflammatory lesions over more than $30 \%$ of the body surface area.

improvement in the clinical symptoms was judged. Three or more points of improvement or persistence of exanthema-free condition for $\geq 6$ months were rated as 'remarkable improvement', two points as 'improvement', one point as 'slight improvement', no change in points or improvement requiring oral steroid treatment within 6 months as "no change", and a minus point change was rated as "deterioration". Patients who had not been cured but stopped visiting the hospital within 6 months were defined as 'drop out'. The evaluation results were recorded and used for later therapy for individual patients. The ratios of patients in whom the symptoms were alleviated by dietary instruction alone and patients who required oral herbal administration were investigated in these records. For those patients whose clinical symptoms after 3 years were confirmed, the gravity of their disease state was evaluated on the same scale as above to compare with the baseline condition.

For those whose symptoms we could not confirm, the results were simply defined as 'unknown'. For the adverse effects of the therapy, not only skin symptoms due to $\mathrm{AD}$, but any subjective and objective abnormalities were carefully examined and recorded.

\section{Kampo Prescriptions}

The following principles were applied in prescriptions:

(i) Byakko-ka-ninjin-to (8) and Oren-gedoku-to (8) for erythema due to inflammatory congestion. Byakkoka-ninjin-to for heavy erythema with hotness with dry skin. Oren-gedoku-to for erythema with heavy congestion which is slightly edematous $(9,10)$;

(ii) Eppi-ka-jutsu-to (8) for exudative eczema or heavily edematous erythema $(9,10)$; Ji-zuso-ippo (Zhi-touchuang-yi-fang) (Table 3) (11-13) for exudative eczema or impetigo on the scalp;

(iii) Jyumi-haidoku-to (Shi-wei-bai-du-tang) (Table 4) (12-14) for folliculitis-like exanthema or pustule $(9,10)$;

(iv) Shofu-san (8) for pruritus;

(v) Ku-Oketsu preparations (qu yu xue ji: drugs for overcoming blood stagnation) for lichen and prurigo $(9,10)$;

(vi) Yokuinin (8) and Unsei-in (8) for dryness and desquamation $(9,10)$;

(vii) Gorei-san (8) or Chorei-to (8) for water retention $(10,15)$;

(viii) Hochu-ekki-to (8) for Ki-kyo (qi xu: deficiency of Qi);

(ix) Keigai-rengyo-to (Jing-jie-lian-qiao-tang) (Table 5) (12-14), Saiko-seikan-to (Chai-hu-qing-gan-tang) (Table 6) (12-14) for constitutional detoxication, KuOkestu preparations for Oketsu (yu xue: blood stagnation; syndrome caused by blood stagnation), for example venous engorgement and dark-blue spots, and for those with constipation $(9,12,14)$; 
Table 3. Components of Ji-zuso-ippo (Japanese; Zhi-tou-chuang-yi-fang in Chinese) extract granules for ethical use (actions: dissolves eczema and impetigo of the scalp)

\begin{tabular}{|c|c|c|c|}
\hline Japanese & Grams & Scientific name & Actions \\
\hline Senkyu & 3.0 & Cnidii Rhizoma & Promotes blood circulation \\
\hline Sojutsu & 3.0 & $\begin{array}{l}\text { Atractylodis Lanceae } \\
\text { Rhizoma }\end{array}$ & Harmonizes water metabolism \\
\hline Rengyo & 3.0 & Forsythiae Fructus & $\begin{array}{l}\text { Anti-bacterial, anti- } \\
\text { inflammatory }\end{array}$ \\
\hline Bofu & 2.0 & Ledebouriellae Radix & Relieves itching, relieves pain \\
\hline Kanzo & 1.0 & Glycrrhizae Radix & $\begin{array}{l}\text { Antitoxic, sedative, protect } \\
\text { digestive system }\end{array}$ \\
\hline Keigai & 1.0 & Schizonepetae Spica & $\begin{array}{l}\text { Relieves pain, relieves itching, } \\
\text { anti-inflammatory }\end{array}$ \\
\hline Koka & 1.0 & Carthami Flos & $\begin{array}{l}\text { Dissolves O-Ketsu, anti- } \\
\text { inflammatory }\end{array}$ \\
\hline Nindo & 0.5 & $\begin{array}{l}\text { Lonicerae Caulis et } \\
\text { Folium }\end{array}$ & Resolves purulent inflammation \\
\hline Daio & 2.0 & Rhei Rhizoma & $\begin{array}{l}\text { Dissolves O-Ketsu, promotes } \\
\text { blood circulation, removes } \\
\text { constipation, anti-inflammatory }\end{array}$ \\
\hline
\end{tabular}

Table 4. Components of Jumi-haidoku-to (Japanese; Shi-wei-bai-du-tang in Chinese) extract granules for ethical use (actions: resolves purulent inflammation)

\begin{tabular}{|c|c|c|c|}
\hline Japanese & Grams & Scientific name & Actions \\
\hline Saiko & 3.0 & Bupleuri Radix & Sedative \\
\hline Kikyo & 3.0 & Platycodi Radix & Anti-inflammatory, resolves pus \\
\hline Senkyu & 3.0 & Cnidii Rhizoma & Promotes blood circulation \\
\hline Bukuryo & 2.0 & Hoelen & Removes excess body fluid \\
\hline Bofu & 2.0 & Ledebouriellae Radix & Relieves itching, relieves pain \\
\hline Kanzo & 1.0 & Glycrrhizae Radix & $\begin{array}{l}\text { Antitoxic, sedative, protects } \\
\text { digestive system }\end{array}$ \\
\hline Keigai & 1.0 & Schizonepetae Spica & $\begin{array}{l}\text { Relieves pain, relieves itching, } \\
\text { anti-inflammatory }\end{array}$ \\
\hline Shokyo & 1.0 & Zingiberis Rhizoma & $\begin{array}{l}\text { Anti-emetic, protects gastric } \\
\text { mucosa }\end{array}$ \\
\hline Dokkatsu & 1.0 & $\begin{array}{l}\text { Aralliae Rhizoma et } \\
\text { Radix }\end{array}$ & Relieves pain \\
\hline Bokusoku & 3.0 & Quercus Cortex & $\begin{array}{l}\text { Relieves pain, relieves itching, } \\
\text { anti-inflammatory, resolves pus }\end{array}$ \\
\hline
\end{tabular}

(x) Toki-shigyaku-ka-goshuyu-shokyo-to (Dang-gui-si-nijia-wu-zhu-Yu-Sheng-Jiang-Tang) (Table 7) (12-14), for chill $(9,12,14)$;

(xi) Toki-shakuyaku-san (8) for chill accompanied by water retention $(9,12,14)$;

(xii) Kami-shoyo-san (8) or Saiko-ka-ryukotsu-borei-to (8) for failure of autonomic nerve regulation $(9,12,14)$.

\section{Results (Tables 8-10)}

Fifty-six male and 84 female patients, with ages ranging from 7 months to 53 years old, were treated. Among them, 48 patients were classified as 'very severe', 54 as 'severe', 31 as 'moderate' and 7 as 'mild'. All of the 'very severe', 53 of the 'severe' patients, 27 of the 'moderate' patients and five of the 'mild' patients had been treated in other hospitals.
Table 5. Components of Keigai-rengyo-to (Japanese; Jing-jie-lian-qiao-tang in Chinese) extract granules for ethical use (actions: anti-inflammatory, reduces troubles by propionibacterium acnes, acts for immune regulation)

\begin{tabular}{|c|c|c|c|}
\hline Japanese & Grams & Scientific name & Actions \\
\hline Ogon & 1.5 & Scutellariae Radix & Anti-inflammatory, cools \\
\hline Obaku & 1.5 & Phellodendri Cortex & Anti-inflammatory \\
\hline Oren & 1.5 & Coptidis Rhizoma & Anti-inflammatory \\
\hline Kikyo & 1.5 & Platycodi Radix & $\begin{array}{l}\text { Resolves sputum and pus, anti- } \\
\text { inflammatory }\end{array}$ \\
\hline Kijitsu & 1.5 & $\begin{array}{l}\text { Aurantii Fructus } \\
\text { Immaturus }\end{array}$ & Protects gastric mucosa \\
\hline Keigai & 1.5 & Schizonepetae Spica & $\begin{array}{l}\text { Relieves pain, relieves itching, } \\
\text { anti-inflammatory }\end{array}$ \\
\hline Saiko & 1.5 & Bupleuri Radix & Sedative when smaller amount \\
\hline Sanshishi & 1.5 & Gardeniae Fructus & Sedative, Mild anti-inflammatory \\
\hline Juk-jio & 1.5 & Rehmanniae Radix & Moisters \\
\hline Shakuyaku & 1.5 & Paeoniae Radix & $\begin{array}{l}\text { Relieves spasm, relieves pain, } \\
\text { anticonvulsive, relieves blood } \\
\text { stasis }\end{array}$ \\
\hline Senkyu & 1.5 & Cnidii Rhizoma & $\begin{array}{l}\text { Promotes blood circulation } \\
\text { resolves pus }\end{array}$ \\
\hline Toki & 1.5 & Angelicae Radix & Promotes blood circulation \\
\hline Hakka & 1.5 & Menthae Herba & Anti-inflammatory, sedative \\
\hline Byakushi & 1.5 & $\begin{array}{l}\text { Angelice Dahuricae } \\
\text { Radix }\end{array}$ & Resolves pus, relieves pain \\
\hline Bofu & 1.5 & $\begin{array}{l}\text { Ledebouriellae } \\
\text { Radix }\end{array}$ & Relieves itching, relieves pain \\
\hline Rengyo & 1.5 & Forsythiae Fructus & Anti-bacterial, anti-inflammatory \\
\hline Kanzo & 1.0 & Glycrrhizae Radix & $\begin{array}{l}\text { Antitoxic, sedative, protects } \\
\text { digestive system }\end{array}$ \\
\hline
\end{tabular}

Of the 140 patients, 37 (26.4\%) did not go proceed to Kampo treatment (four of the 'very severe', 13 of the 'severe', 17 of the 'moderate' and three of the 'mild' cases). Of these patients, 21 dropped out for reasons other than changes in the disease conditions (e.g. because of other time commitments), one ceased to visit our hospital because the symptoms disappeared within 2 months without receiving Kampo therapy. On telephone contact it was found that two among them were improved remarkably with diet therapy alone, two were improved, one was slightly improved, and four were unchanged (the other 12 patients were 'unknown', because contact could not be established). Among those who were treated in our outpatient clinic for more than 6 months, there were eight patients whose symptoms were remitted by change in dietary habit alone, with continuation of Western conventional therapy (5.7\% of total patients). For the group of patients who did not wish to take Kampo medicine but followed the diet recommendations during the observation period, the diet change was slightly effective in seven patients $(5 \%)$, with no effect in one $(0.7 \%)$ patient. After 3 years followup, symptoms of those patients were remarkably improved in eight patients, slightly improved in one and unknown in seven. The remaining 103 patients $(73.6 \%)$ proceeded to receive oral Kampo preparations. The classification of these remaining patients was: 44 'very severe', 41 'severe', 14 'moderate' and four 'mild' cases. After 6-12 months follow-up, remarkable improvement was seen in 25 patients $(17.9 \%$ of the total), 
Table 6. Components of Saiko-seikan-to (Japanese; Chai-hu-qing-gan-tang in Chinese) extract granules for ethical use (actions: reduces recurrence of tonsillitis, eczema, or inflammation, anti-allergic)

\begin{tabular}{|c|c|c|c|}
\hline Japanese & Grams & Scientific name & Actions \\
\hline Ogon & 1.5 & Scutellariae Radix & Anti-inflammatory, cools \\
\hline Obaku & 1.5 & Phellodendri Cortex & Anti-inflammatory \\
\hline Oren & 1.5 & Coptidis Rhizoma & Anti-inflammatory \\
\hline Kikyo & 1.5 & Platycodi Radix & $\begin{array}{l}\text { Resolves sputum and pus, } \\
\text { anti-inflammatory }\end{array}$ \\
\hline Karokon & 1.5 & Trichosanthis Radix & Anti-inflammatory \\
\hline Goboshi & 1.5 & Arctii Fructus & Anti-inflammatory, resolves pus \\
\hline Saiko & 2.0 & Bupleuri Radix & Sedative when smaller amount \\
\hline Sanshishi & 1.5 & Gardeniae Fructus & Sedative, mild anti-inflammatory \\
\hline Juku-Jio & 1.5 & Rehmanniae Radix & Moistens \\
\hline Shakuyaku & 1.5 & Paeoniae Radix & $\begin{array}{l}\text { Relieves spasm, relieves pain, } \\
\text { anticonvulsive, relieves blood } \\
\text { stasis }\end{array}$ \\
\hline Senkyu & 1.5 & Cnidii Rhizoma & $\begin{array}{l}\text { Promotes blood circulation, } \\
\text { resolves pus }\end{array}$ \\
\hline Toki & 1.5 & Angelicae Radix & Promotes blood circulation \\
\hline Hakka & 1.5 & Menthae Herba & Anti-inflammatory, sedative \\
\hline Rengyo & 1.5 & Forsythiae Fructus & Anti-bacterial, anti-inflammatory \\
\hline Kanzo & 1.5 & Glycrrhizae Radix & $\begin{array}{l}\text { Antitoxic, sedative, protects } \\
\text { digestive system }\end{array}$ \\
\hline
\end{tabular}

Table 7. Components of Toki-shigyaku-ka-goshuyu-shokyo-to (Japanese; Dang-gui-si-ni-jia-wu-zhu-yu-sheng-jiang-tang in Chinese) extract granules for ethical use (actions: reduces chill, promotes blood circulation)

\begin{tabular}{|c|c|c|c|}
\hline Japanese & Grams & Scientific name & Actions \\
\hline Taiso & 5.0 & Zyzyphi Fructus & $\begin{array}{l}\text { Antitoxic, strengthens digestive } \\
\text { system }\end{array}$ \\
\hline Keihi & 3.0 & Cinnamoini Cortex & Promotes blood circulation \\
\hline Shakuyaku & 3.0 & Paeoniae Radix & $\begin{array}{l}\text { Relieves spasm, relieves pain, } \\
\text { anticonvulsive, relieves blood } \\
\text { stasis }\end{array}$ \\
\hline Toki & 3.0 & Angelicae Radix & Promotes blood circulation \\
\hline Mokutsu & 3.0 & Akebiae Caulis & Removes excess body fluid \\
\hline Kanzo & 2.0 & Glycrrhizae Radix & $\begin{array}{l}\text { Antitoxic, sedative, protects } \\
\text { digestive system }\end{array}$ \\
\hline Goshuyu & 2.0 & Evodiae Fructus & Anti-emetic \\
\hline Saishin & 2.0 & Asiasari Radix & Relieves pain \\
\hline Shokyo & 1.0 & Zingiberis Rhizoma & $\begin{array}{l}\text { Anti-emetic, protects gastric } \\
\text { mucosa }\end{array}$ \\
\hline
\end{tabular}

improvement was seen in $30(21.4 \%)$, slight improvement in 21 $(15 \%)$, unchanged in $14(10 \%)$ and aggravation of condition in four $(2.9 \%)$. There were withdrawals: seven patients were unassessable because they could not visit our clinic, one was improved within 6 months but subsequent attempts at contact failed and one became unassessable because of heavy treatment for complications. Among these 103 patients, the number treated by Kampo by previous physicians was 22 (15.7\% of total), among whom our Kampo treatment was markedly to slightly effective in 19 patients $(13.6 \%)$. All four patients with aggravated conditions complained of mental stress: of these four, the aggravation in one coincided with exposure to toxic chemicals used for remodeling of his house and the other three all failed in changing their diets (because of the difficulty in quitting sweets). Thus, we did not consider their conditions to be aggravated by Kampo treatment. Kampo was therefore not discontinued and the symptoms improved with better compliance to the diet instructions. There were no severe adverse effects due to Kampo treatment.

\section{Overall Evaluation}

Our approach was markedly effective in 25 patients $(17.9 \%$ of total), effective in $30(21.4 \%)$ and slightly effective in 21 (15\%). Our approach had no effect in 18 patients $(12.9 \%)$.

After 3 years of follow-up, our approach was markedly effective in 38 patients $(27.1 \%$ of total), effective in $29(20.7 \%)$, slightly effective in $14(10 \%)$ and unknown in $10(7.1 \%)$.

There were no serious adverse effects due to Kampo sessions with no subjective or objective (laboratory examinations) abnormalities.

\section{Discussion}

\section{How Firm is the Evidential Basis for Conventional AD Therapy?}

$\mathrm{AD}$ is a complex, multifactorial disease for which definite guidelines of treatment have yet to be established. In principle, the treatment mode will differ according to the grade of disease. In mild cases, the mainstay of treatment is skin-care using emollients. Dermatologists in recent years, however, have debated hotly about how to treat those patients whose symptoms recur after this basic measure and also those who present with higher-grade symptoms, either from the beginning or after aggravation. The conventional wisdom among dermatologists centers around a guideline such as follows $(16,17)$ :

1 As the first line, providing adequate explanation of the nature of disease as well as advice on avoiding irritants, topical steroids for the skin lesion and oral antihistamines for sedation are recommended;

2 As the second line, removal of possible allergens and ultraviolet therapy could be considered;

3 For the third line treatment of grave conditions, immunosuppressants such as systemic corticosteroids and cyclosporin A could be considered.

In one British guideline, Chinese herbal medicine is included in the third-line treatment (16). In Japan, the consensus guideline can be outlined as below:

$1^{\prime}$ As the first line, it is emphasized that the use of various topical steroids should be fine-tuned according to the degree of skin lesion, and the use of anti-histamines not only for sedation but to directly reduce pruritus is accepted, in addition to guideline 1 , above.

$2^{\prime}$ As the second line, systemic use of anti-allergic drugs with anti-cytokine properties are suggested in addition to guideline 2, above, but ultraviolet therapy is reserved for third line. 
Table 8. The evaluation results after 6 months to one year follow-up

\begin{tabular}{lccccccc}
\hline Evaluation & \multicolumn{3}{c}{ Kampo (-) } & & \multicolumn{3}{c}{ Kampo (+) } \\
\cline { 2 - 3 } & $\begin{array}{c}\text { patients } \\
(\mathrm{n}=37)\end{array}$ & $\%$ (group) & \% (total) & & $\begin{array}{l}\text { patients } \\
(\mathrm{n}=103)\end{array}$ & $\%$ (group) & $\%$ (total) \\
\hline remarkable improvement & 8 & 21.6 & 5.7 & & 25 & 24.3 & 17.9 \\
improvement & 0 & 0.0 & 0.0 & & 30 & 29.1 & 21.4 \\
slight improvement & 7 & 18.9 & 5.0 & & 21 & 20.4 & 15.0 \\
no change & 1 & 2.7 & 0.7 & & 14 & 13.6 & 10.0 \\
deterioration & 0 & 0.0 & 0.0 & & 4 & 3.9 & 2.9 \\
drop out & 21 & 56.8 & 15.0 & & 9 & 8.7 & 6.4 \\
\hline
\end{tabular}

Table 9. Comparison between groups with or without previous Kampo among patients who received oral Kampo prescriptions

\begin{tabular}{lccccccc}
\hline Evaluation & \multicolumn{3}{c}{ previous Kampo (-) } & & \multicolumn{3}{c}{ previous Kampo (+) } \\
\cline { 2 - 3 } & $\begin{array}{c}\text { patients } \\
(\mathrm{n}=81)\end{array}$ & $\%$ (group) & $\%\left(\right.$ total $\left.^{*}\right)$ & & $\begin{array}{c}\text { patients } \\
(\mathrm{n}=22)\end{array}$ & $\%$ (group) & $\%\left(\right.$ total $\left.^{*}\right)$ \\
\hline remarkable improvement & 17 & 21.0 & 12.1 & & 8 & 36.4 & 5.7 \\
improvement & 23 & 28.4 & 16.4 & & 7 & 31.8 & 5.0 \\
slight improvement & 17 & 21.0 & 12.1 & & 4 & 18.2 & 2.9 \\
no change & 12 & 14.8 & 8.6 & & 2 & 9.1 & 1.4 \\
deterioration & 3 & 3.7 & 2.1 & & 1 & 4.5 & 0.7 \\
drop out & 9 & 11.1 & 6.4 & & 0 & 0.0 & 0.0 \\
\hline
\end{tabular}

*Total, 140, includes 37 patients without administration of Kampo formula.

Percentages may not sum to 100 , because of rounding.

Table 10. The evaluation results after 3 years follow-up*

\begin{tabular}{lccccccc}
\hline Evaluation & \multicolumn{3}{c}{ Kampo (-) } & & \multicolumn{3}{c}{ Kampo (+) } \\
\cline { 2 - 3 } & $\begin{array}{c}\text { patients } \\
(\mathrm{n}=37)\end{array}$ & $\%$ (group) & $\%$ (total) & & $\begin{array}{c}\text { patients } \\
(\mathrm{n}=103)\end{array}$ & $\%$ (group) & $\%$ (total) \\
\hline remarkable improvement & 8 & 21.6 & 5.7 & & 38 & 36.9 & 27.1 \\
improvement & 0 & 0.0 & 0.0 & & 29 & 28.2 & 20.7 \\
slight improvement & 1 & 2.7 & 0.7 & & 14 & 13.6 & 10.0 \\
no change & 0 & 0.0 & 0.0 & & 3 & 2.9 & 2.1 \\
deterioration & 0 & 0.0 & 0.0 & & 0 & 0.0 & 0.0 \\
unknown & 7 & 18.9 & 5.0 & & 10 & 9.7 & 7.1 \\
drop out & 21 & 56.8 & 15.0 & & 9 & 8.7 & 6.4 \\
\hline
\end{tabular}

*Percentages may not sum to 100 , because of rounding. 
3' For the third line, in addition to guideline 3, above, antimycotic agents are suggested for possible mycosis in the intestine, ultraviolet therapy, psychotherapy and antiallergic treatment for metals are recommended $(18,19)$. Systemic use of immunosuppressive agents is not highly recommended in Japan, and topical use of tacrolimus by professional dermatologists with informed consent has been recommended (20).

Even in Japan, the status of Kampo medicine in this system has not been settled yet.

To date, however, there has been little solid evidential basis for either of the approaches above as systematic strategies, at least on the standard model of evidence-based-medicine (EBM). The number of randomized control trials (RCT) on the efficacy of each agent seems to be increasing, but they are still problematic. This is because it is difficult to define the proper endpoint for this disease, and also any clinical trials for $\mathrm{AD}$ with a duration of less than 2 years could be of questionable validity. For example, Hoare et al. (16) analyzed 1165 RCTs to evaluate various modalities for prevention and treatment of AD. They concluded that oral cyclosporin, topical steroids, psychological approach and ultraviolet therapy have been shown to have positive evidence of efficacy. We think their conclusions are not at odds with the clinical experience of a majority of dermatologists. However, both endpoint and trial periods vary among these studies; therefore, we cannot accept those authors' evaluation without reservation. Some of the above treatments are easy to prove effective by conventional RCT when their short-term effects on skin symptoms only are evaluated. Experienced dermatologists are well aware of the danger of long-term use of those agents which are effective in the short-term and are targeted for the skin symptoms alone. Specifically, we suspect that oral immunosuppressive agents may even be proven harmful by RCT if used chronically by taking skin symptoms as the sole endpoint.

Topical corticosteroids, first introduced in the early 1950s, have since remained the mainstay of current AD therapy. A small amount of high-quality evidence is now available $(7,16,21-38)$. However, as they are superficially so effective, particularly for those patients whose trigger factor is one which can be easily removed, and also inflammation is temporary, both physicians and patients tend to become dependent on them. When development of more severe lesions with atypical symptoms occurs, for example, flexural eczema in the limbs turned into facial intractable erythema, topical corticosteroids would become less effective. The present EBM is still not subtle enough to address such problems as changed effect of one agent according to the situation of an individual patient during the chronic course of a complex disease. For example, Hoare et al. (16) stated that they could find no RCT evidence to support different approaches to using topical corticosteroids such as comparing shorter bursts of strong preparations versus longer-term treatment with weaker preparations.

This evidential situation is similar for other conventional drugs. For example, although anti-histamines are conventionally employed with topical corticosteroids as the first-line therapy for $\mathrm{AD}$, there seems to be little high-quality evidence available to prove their efficiency in AD itself (39-60). As to immunosuppressive agents represented by cyclosporin, evidence for their long-term benefits are still lacking, although they have been used for AD patients on the basis of their shortterm effects (61-64). Recently, topical calcineurin inhibitors, namely tacrolimus and pimecrolimus, have been added to the repertoire in first line therapy (65), as they seem to be free from the adverse effects seen when corticosteroids were used protractedly and they also appear to actually inhibit the progress of the disease (66-69). However, we agree to the recommendation for their careful use, as their long-term efficacy and adverse effects have not been elucidated yet (70).

Thus, there are two major pitfalls in applying the standard RCT approach to AD, namely, duration of the trial and endpoint. As pointed out above, short-term effectiveness may convert to long-term harm, and skin symptoms may not even be taken as the true endpoint of $\mathrm{AD}$, but only as one of the surrogate endpoints. Indeed, some groups have already discussed the issue that data from large scale RCTs do not necessarily provide evidence useful for actual clinical practice in dealing with $\mathrm{AD}$ patients $(38,71)$. In addition, there is one more important issue in AD when RCT is to be planned and evaluated. It is that $\mathrm{AD}$ may not even represent a single disease entity, but may instead represent common skin expressions of different pathophysiological states. As randomization is only possible for a homogeneous population of patients, taking skin symptoms as the target would be misleading if the underlying conditions were heterogeneous.

Although the conventional approach utilizing drugs such as those listed above brings many patients' conditions under control, there are definite subgroups of patients who become intractable by this approach. No serious attempt seems to have been made to statistically estimate the actual number of such patients, because it is difficult to judge whether those patients should be regarded as 'intractable cases' or just treatment failures. But experience of professional dermatologists would settle around the figure of as much as $40 \%$ of AD patients in this category, and there have been several reports showing that similar percentages of patients turn to non-conventional CAM therapies (72-74).

Such a situation may even allow us to cast doubt on the conventional guideline itself, especially the 'third line' agents listed above. Although we would not side with those 'extremists' who claim that the very use of systemic corticosteroids and immunosuppressant drugs or even chronic use of topical steroids have caused the spread of intractable AD over the last few decades, we should admit at the same time that there is no definite evidence that disproves their claims. Thus, although we ourselves have generally sided with the consensus, or conventional, guideline, we are by no means satisfied with its evidential basis. We would not, at least for the moment, abandon topical corticosteroids as a first line drug (along with diet) for AD patients. But it does not mean that we take it as a 'central' or 'mainstay' remedy that should come before everything else. Topical steroids should be seen as one of the first options to 
relieve the symptoms, which should, however, not be used indefinitely. Thus, we roughly agree that the conventional guideline has evidential basis up to the first and the second line modalities, but no more. We would like to combine the guidelines 1 and 2 above as recommended 'first-line' therapy for $\mathrm{AD}$. We are in opposition to the easy use of systemic corticosteroids and immunosuppressive agents. They should not even be regarded as the second-line therapy, but be reserved as the last resort to be used in the short term.

\section{How Should Kampo be Viewed as Treatment Modality for AD?}

\section{First or Second Line?}

We believe that we have established that our 'Diet and Kampo' approach can bring cure for $>50 \%$ of patients considered to be intractable with the conventional approach. Since we agree that the conventional approach, especially topical steroids, is effective for the majority of AD patients in the short term, we opt to include it as first-line therapy along with diet change, and thus Kampo is reserved as a second-line regimen, to replace systemic use of corticosteroids and immunosuppressive agents. We think our approach can therefore be adopted and tried in the West. On the other hand, as mentioned above, in Japan (and other Asian countries) there are 'fundamentalist' Kampo physicians who contend that $\mathrm{AD}$ can be cured with Kampo alone. However, from our own experience, Kampo alone as a first-line regimen seems no more effective than the standard first-line therapy, though again we should be cautious about individual differences: there seem to be a subgroup of patients for whom Kampo is more effective as the single first-line regimen. The view that Kampo is not a magic bullet is partially supported by the case studies presented above, which show that a substantial proportion of patients who visit our clinic have failed with Kampo. We would thus not suggest that large-scale standard RCT should be planned to compare the effect of any single specific Kampo formula against topical corticosteroids in a heterogeneous population of patients with $\mathrm{AD}$.

Although much attention has recently been focused on Kampo herbal medicine for $\mathrm{AD}(6,8-11,14,15,75-102)$, there are only a few reports examining the efficacy of Kampo in a first-line treatment setting, as reviewed by Armstrong and Ernst (97). Sheehan et al. (98-100) reported the usefulness of the composite herbs of Zemaphyte ${ }^{\circledR}$ by a randomized, doubleblind cross-over trial. However, a subsequent trial by Fung et al. (102) failed to show its superiority over placebo. These reports are not very surprising to us, though we believe Kampo alone can be at least more effective than placebo. Zemaphyte's ${ }^{\circledR}$ composite herbs include Bofu (Ledebouriella seseloides) and other anti-pruritic herbs, and Jio (Rehmannia glutinosa) and other anti-inflammatory and anti-congestive herbs. Their pharmacological actions are being elucidated by modern Western techniques (103-108). Some of these components overlap with those in our formulae, but generally we regard them as alleviating agents for superficial symptoms, so we do not expect them to be more useful than topical steroids and oral anti-histamines as first-line drugs in treating those patients who could well be cured by conventional treatment.

We have not been able to find any previous reports in the literature where Kampo has been systematically used specifically as second-line treatment for those in whom the standard treatment has failed. Our report seems to be the first to show its actual effectiveness in this setting and also to show that Kampo treatment can smoothly complement conventional modes of therapy.

\section{Kampo Paradigm and $A D$}

As seen in the case studies, Kampo therapy for AD patients is not straightforward. It is the rule rather than the exception that we have to resort to plural formulae before bringing a patient's conditions under control. The Kampo remedies we use include Shofu-san, Ji-zuso-ippo and Eppi-ka-jutsu-to. These remedies are for the treatment of symptoms exhibited on the body surface, but very often we use such formulae as Hochu-ekki-to, intending to simultaneously improve patients' general conditions. Even for the same disease entity in the Western concept of medicine, we prescribe different herbal preparations for individual patients according to the overall presentation of each patient, and the prescription is changed with changes in the main pathology of the patient during the course of treatment. This approach of fine-tuning using multiple formulae is the major cause of difficulty in performing double blind RCT to investigate the usefulness of herbal preparations for a complex disease such as AD.

Since the pathogenesis of the disease itself is still obscure, the conventional treatment is symptomatic in principle. Aside from the use of anti-histamines for pruritus, the very use of steroids and other immunosuppressive agents is aimed at suppressing manifestations of inflammatory reactions and not at correcting the underlying disorders. Simply put, it is analogous to the situation of early 20th century medicine against influenza, when the very existence of viruses was unknown, while aspirin had been used to suppress fever with reasonable success. This symptomoriented approach is no doubt reasonable in Western analytical medicine, where no specific agent should or could be employed to radically cure disorders of which we do not have enough pathogenetic knowledge. However, such a strategy will become problematic if adverse effects of the drugs used to suppress superficial symptoms override correction of the underlying conditions. Those conditions would include putative abnormality in the immune system, failure of the autonomic nervous regulatory functions and imbalance of the endocrine system, all of which have been implicated for AD. The fact that Kampo with diet therapy can bring about cure for many of those patients refractory to the conventional treatment suggests, though of course does not prove, that the Kampo regimens are affecting not the superficial symptoms but the underlying pathogenetic conditions of these patients. While there is no conventional treatment aimed at these underlying conditions, Kampo should be considered seriously as a treatment modality directed at an alternative target. In doing so, clinical trials should be designed so as not to 
select as endpoint the surface symptoms which can be treated in the short-term by steroids or immunosuppressive agents.

Besides the difference of treatment target as above, modern Western medicine can be supplemented in another way by the Kampo approach. That is, the long-term view on the patient as an individual. Experienced dermatologists are aware that there are several subgroups in AD patients, and various subsets and temporal phases in its clinical manifestations. For example, patients having psychological problems are quite different from those with dietary habit problems. Likewise, the disease phase in one individual patient is different whether inflammatory reactions are the main manifestation or not. When we resort to Kampo therapy, we choose from a wide variety of Kampo repertoires those which we consider best for each individual patient in certain specific conditions. These 'conditions' are called 'Sho' in Kampo (12). We would admit that identifying Sho is still rather intuitive, and more art than science at present. One way for Kampo therapy to become more universally applicable is to develop more analytical descriptions of the patient's Sho for which only certain kinds of Kampo formulae could be agreed to be used by experienced Kampo physicians. Doubleblind placebo controlled trial could become valid if Sho descriptions could become more objective.

\section{How Should Kampo be Integrated Into the Treatment Strategy for AD?}

\section{Proposal: An Alternative Guideline}

Based on the presentation and discussions above, we would like to propose an interim alternative guideline for AD therapy with some proposal for its evaluation by clinical trials. Our alternative guideline is as below:

1. First, discuss with patients their general lifestyle, especially their diet. Propose to the patient that AD could be cured 'from within', or by returning to a better state of his/her mind-body, by, specifically, returning to healthier dietary habits. Try to ask the patient to understand that skin inflammation is sometimes an expression of a deeper imbalance of his/her mind-body if there are no obvious allergens or irritants. Try to provide good supportive care for those patients with psychological problems.

2. Try topical steroids, tacrolimus ointment and emollients to alleviate the skin symptoms. Try anti-histamines in cases of severe pruritus. Try Kampo regimens if these regimens fail.

3. Systemic administration of corticosteroids and immunosuppressant drugs should be reserved only for patients with whom all the above measures have failed. Even when they are to be introduced, they should be used only for very limited duration in order to avoid any adverse effects due to protracted use. Kampo can be continued with these agents as several Kampo prescriptions can alleviate adverse effects of these agents.

Essentially, this is a proposal to place Kampo as the secondline treatment before systemic corticosteroids and immunosuppressant agents. Recent epidemiological evidence has established the long suspicion that use of systemic corticosteroids increases the incidence of malignancy (109).

We would like to add that we have used Kampo for many patients as first-line with reasonable success, and so after further studies we may even place it as a first-line therapy. But, for the time being, we would recommend the above guidelines, as conventional therapy is effective in many cases if carried out within the framework of psycho-physical care and serious improvement in lifestyle to avoid trigger factors. Also, we would like to point out that Kampo herbs are limited resources, abuse of which will deprive future patients of opportunities to benefit from them.

\section{How to Evaluate the Alternative Guideline Using Kampo?}

We think the most important but problematic aspect of Kampo therapy proposed above is that Kampo presupposes the use of plural formulae for each individual patient. Kampo therapy is not a treatment using a single mono-component drug but a treatment 'session' using various multi-component herbs.

The most appropriate method to evaluate the efficacy of such a guideline would be modified 'N-of-1' trial (110-116), where the effect of a Kampo 'session' by one physician is evaluated for one individual patient against placebo. The trial will comprise several sequential periods during which Kampo sessions using real herbs or placebo are alternated, in a randomized double-blind manner. We have yet to start such a trial, because there are still no good placebo preparations for different specific Kampo formulae. But we are considering the introduction of capsule formulations to actually carry out such a trial.

\section{A Further Proposal of Trial Based on the Kampo Paradigm}

We have shown in the case series that our Kampo formulae are not necessarily prescribed for any specific 'symptoms' of AD in the modern Western sense. We have also suggested that AD may be seen not as a single disease entity, but may be regarded as heterogeneous pathophysiological conditions sharing several characteristic skin symptoms. If that were really the case, AD patients should be classified into several subgroups. Such classification will be established based on Western scientific pathophysiology in the future. But even without having such a 'scientific' classification, we would like to propose here that there seems to be one rather distinct subgroup in AD patients from the viewpoint of Kampo. It is a group of patients who exhibit the Sho we call in Kampo O-Ketsu ('dirty blood'). These patients are usually obese with high fat/caloric intake (the 'fried potatoes' group). We hypothesize that AD may develop in these people when they reach the stage exhibiting 'O-Ketsu' Sho. For these patients, we believe, such formulae as Keishi-bukuryo-gan are effective with diet changes. Standard RCT may even be designed to check the effect of one single Kampo formula against placebo if such a classification of patients according to Sho could be introduced. Such a trial design of RCT is, however, the exception and not the rule for Kampo treatment, as it is a rule and not the exception that Sho changes during the period of treatment. 
Another possible trial design is one in which the method of the present report is systematized. For example, the guideline above is applied first to all patients, those who failed by the first-line treatment are randomized into two groups where the only difference is presence or absence of Kampo treatment. In such a design, not only the symptoms but also quality of life and necessity of corticosteroids should be added as evaluation points.

As pointed out before, not only the length of trial period but the timing at which the effect is evaluated is crucial in assessing any treatment modes for AD. For Kampo herbs in particular, with rare exceptions such as Byakko-ka-ninjin-to, it takes months for their effects to become apparent. Evaluation of the effects of any agents tried for AD is not only important for confirming their real efficacy and safety but also from the standpoint of patients themselves, for whom short-term disappearance of symptoms does not mean much. We have so far not discussed the detail of the diet therapy essentially accompanying our Kampo therapy. But long-term evaluation is particularly important for our Kampo diet therapy, which, unlike that of simple removal of allergens, takes years for its effects to become apparent. Thus, we propose that in clinical trials of any agents for $\mathrm{AD}$, their effects should be evaluated after 3 years as a minimum. We are convinced that Kampo and diet approach is not inferior to any other modalities if the long-term viewpoint is taken in evaluation.

\section{The Art of Kampo}

In proposing such a guideline and plan for clinical trials, we would like to make a final remark of caution. We have provided evidence in this Review that Kampo therapy is effective only when administered by experienced practitioners. Therefore, the guideline above would also state that Kampo sessions should be managed by an expert. Traditional Kampo therapy, being like an art or craft, unlike the science and technology of modern Western medicine, is hard to gain expertise in, since it depends not on objective measures and techniques but on subjective observations, experience and oral instruction by Kampo masters. In Japan, a new generation of doctors is now emerging, who are educated in modern medical schools but learned Kampo from existing masters. These doctors, ourselves included, are trying to integrate modern and traditional approaches. The consensus being formed is that diagnosis should be fully based on modern analytical science, but in the treatment we should introduce Kampo upon understanding its pharmacological effects and patients' pathophysiological conditions both in terms of modern and traditional medicine. Thus, as seen above, we use Kampo on symptoms understood in terms not only in modern Western medicine but also in traditional Kampo terms. For example, we use Hochu-ekki-to to enhance $\mathrm{Ki}(\mathrm{Qi})$ for those patients who are in the condition (Sho) of Ki-kyo ('hollow spirit'). As can be easily understood, while there is still no objective parameter to measure $\mathrm{Ki}$ in modern medicine, this intuitive approach has great danger of being abused. Expertise is the fundamental condition for the sound practice of Kampo. We do not wish to be mystical in stating this, however, since expertise of doctors is a definite determinant of cure in any medical practice, regardless of its Eastern or Western origins. In addition, even in the Kampo repertoires, there are several formulae which do not require much mystical insight in prescribing them: for example, Hochu-ekki-to can be rather safely used by non-expert physicians to 'encourage' those AD patients who are discouraged (hollow-spirited). Some of Kampo Sho is not mystical at all, but even commonsensical. From a different viewpoint, we would also like to emphasize that an element of art in medicine becomes inevitable whenever the very nature of the disease treated is mysterious. $\mathrm{AD}$ is one representative example of such disorders. In treating a 'mysterious' disease like AD and, for example, many of the autoimmune diseases, good intuition about the individual patient's changing conditions is still an essential prerequisite for a clinical physician to provide beneficial support to him/her. We contend that artful Kampo treatment is a strategy to be seriously considered for AD patients. We would welcome any Western dermatologists who wished to visit our clinic to learn Kampo with us and attain the minimum level of expertise. Widespread application of the art of Kampo would make it possible to test its actual effectiveness by such trial methods as proposed above at multiple institutions around the world.

\section{References}

1. Hanifin JM, Rajka G. Diagnostic features of atopic dermatitis. Acta Dermatovener (Stockholm) (Suppl)1980;92:44-7.

2. Costa C, Rilliet A, Nicolet M, Saurat J-H. Scoring atopic dermatitis: The simpler the better? Acta Derm Venereol (Stockholm) 1989;69:41-5.

3. European Task Force on Atopic Dermatitis. Severity Scoring of Atopic Dermatitis: The SCORAD Index. Consensus report of the European Task Force on Atopic Dermatitis. Dermatology 1993;186:23-31.

4. Berth-Jones J. Six area, six sign atopic dermatitis (SASSAD) severity score: a simple system for monitoring disease activity in atopic dermatitis. Br J Dermatol 1996;135(Suppl 48):25-30.

5. Furue M. A guideline for the treatment of atopic dermatitis. http://www kyudai-derm.org/atopy/atopy.html (in Japanese).

6. Ishii M, Kobayashi H, Mizuno N, Takahashi K, Yamamoto I. Japanese herb treatments of adult atopic dermatitis by diet and Japanese herb remedy - Evaluation of disappearance of disease phases. In Dermatological Oriental Medicine Study Group, editors, State of Herb Treatments in Dermatology 9. Tokyo: Sogoigaku Co., 1997; 63-77 (in Japanese).

7. Furue M, Terao A, Rikihisa W, Urabe K, Kinukawa N, Nose Y, et al. Clinical dose and adverse effects of topical steroids in daily management of atopic dermatitis. Br J Dermatol 2003;148:128-33.

8. Kobayashi, H, Takahashi K, Mizuno N, Kutsuna H, Ishii M. An Alternative Approach to Atopic Dermatitis. I. Case-Series Presentation. Evidencebased Complementary and Alternative Medicine 2004;1:49-62.

9. Takahashi K. Outline of Kampo therapy for skin diseases. Based on the conceptual system of traditional Chinese medicine. Skin Res 1997;39: 1-23 (in Japanese).

10. Takahashi K. Kampo therapy in Dermatology. Treatment for skin symptoms (I). Kampo Study 2004;388:126-9 (in Japanese).

11. Ninomiya F. Ji-zuso-ippo for adult atopic dermatitis. Jpn J Oriental Med 1990;40:54-5 (in Japanese).

12. Terasawa K. KAMPO, Japanese-Oriental Medicine, Insights from Clinical Cases. Tokyo: K.K. Standard McIntyre, 1993.

13. Tei S. Japanese-English Dictionary of Oriental Medicine. Tokyo: Iseisha, 1993.

14. Kuwano S. Basic Knowledge and Clinical Use of Kampo Prescriptions for Physicians and Pharmacists. Tokyo: Hirokawa Publishing Co., 1997 (in Japanese). 
15. Ninomiya F. Summary and Kampo therapy in future. In Symposium for treatment of atopic dermatitis. The Kampo. 2000;6:42-3 (in Japanese).

16. Hoare C, Li Wan Po A, Williams H. Systematic review of treatments of atopic eczema. Health Technol Assess 2000;4;(37).

17. McHenry P, Williams HC, Bingham EA. Treatment of atopic eczema. Br Med J 1995;310:843-7.

18. Ikezawa Z. Basic and Clinical Aspects of adult atopic dermatitis. Biotherapy 1999;13:961-9 (in Japanese).

19. Baron ED, Barzilal D, Johnston G, Kawashima M, Takigawa M, Nakagawa $M$, et al. Atopic dermatitis management: comparing the treatment patterns of dermatologists in Japan, USA and UK. $\mathrm{Br} J$ Dermatol 2002;147:710-5.

20. Furue M, Furukawa F, Hide M, Takehara K. Guidelines for therapy for atopic dermatitis 2004. Jpn J Dermatol 2004;114:135-42 (in Japanese).

21. Van der Ploeg DE. Betamethasone dipropionate ointment in the treatment of psoriasis and atopic dermatitis: a double-blind study. South Med J 1976;69:862-3.

22. Roth HL, Brown EP. Hydrocortisone valerate. Double-blind comparison with two other topical steroids. Cutis 1978;21:695-8.

23. Sudilovsky A, Muir JG, Bocobo FC. A comparison of single and multiple application of Halcinonide cream. Int J Dermatol 1981;20:609-13.

24. Lupton ES, Abbrecht MM, Brandon ML. Short-term topical corticosteroid therapy (halcinonide ointment) in the management of atopic dermatitis. Cutis 1982;30:671-5.

25. Sefton J, Joder JS, Kyriakopoulos AA. Clinical evaluation of hydrocortisone valerate $0.2 \%$ ointment. Clin Ther 1984;6:282-93.

26. Wahlgren CF, Hägermark O, Bergström R, Hedin B. Evaluation of a new method of assessing pruritus and antipruitic drugs. Skin Pharmacol 1988;1:3-13.

27. Stalder JF, Fleury M, Sourisse M, Rostin M, Pheline F, Litoux P. Local steroid therapy and bacterial skin flora in atopic dermatitis. Br J Dermatol 1994;131:536-40.

28. Lawlor F, Black AK, Greaves M. Prednicarbate $0.25 \%$ ointment in the treatment of atopic dermatitis: A vehicle-controlled double-blind study. J Dermatol Treat 1995;6:233-5.

29. Lebwohl M. Efficacy and safety of fluticasone propionate ointment, 0.005\%, in the treatment of eczema. Cutis 1996;57(2 Suppl):62-8.

30. Sears HW, Bailer JW, Yeadon A. Efficacy and safety of hydrocortisone buteprate $0.1 \%$ cream in patients with atopic dermatitis. Clin Ther 1997;19:710-9.

31. Maloney JM, Morman MR, Stewart DM, Tharp MD, Brown JJ, Rajagopalan R. Clobetasol propionate emollient $0.05 \%$ in the treatment of atopic dermatitis. Int J Dermatol 1998;37:142-144.

32. Ainley-Walker PF, Patel L, David TJ. Side to side comparison of topical treatment in atopic dermatitis. Arch Dis Child 1998;79:149-52.

33. Van der Meer JB, Glazenburg EJ, Mulder PG, Eggink HF, Coenraads PJ. The management of moderate to severe atopic dermatitis in adults with topical fluticasone propionate. The Netherlands Adult Atopic dermatitis Study Group. Br J Dermatol 1999;140:1114-21.

34. Friedlander SF, Hebert AA, Allen DB. Safety of fluticasone propionate cream $0.05 \%$ for the treatment of severe and extensive atopic dermatitis in children as young as 3 months. J Am Acad Dermatol 2002;46:387-93.

35. Thomas KS, Armstrong S, Avery T, Po ALW, O'Neill C, Young S, Randomized controlled trial of short burst of a potent topical corticosteroid versus prolonged use of a mild preparation for children with mild or moderate atopic eczema. Br Med J 2002;324:768-71.

36. Hanifin JT, Gupta AK, Rajagopalan R. Intermittent dosing of fluticasone propionate cream for reducing the risk of relapse in atopic dermatitis patients. Br J Dermatol 2002;147:528-37.

37. Berth-Jones J, Damstra RJ, Golsch S, Liveden JK, Van Hooteghem O, Allegra F, et al. Twice weekly fluticasone propionate added to emollient maintenance treatment to reduce of relapse in atopic dermatitis; randomized, double blind, parallel group study. Br Med J 2003;326:367-70.

38. Hanifin JM, Cooper KD, Ho VC, Kang S, Krafchik BR, Margolis DJ, et al. Guidelines of case for atopic dermatitis. J Am Acad Dermatol 2004;50:391-404.

39. Savin JA, Paterson WD, Adam K, Oswald I. Effects of trimeprazine and trimipramine on nocturnal scratching in patients with atopic eczema. Arch Dermatol 1979;115:313-5.

40. Klein GL, Galant SP. A comparison of the antipruritic efficacy of hydroxyzine and cyproheptatidine in children with atopic dermatitis. Ann Allergy 1980:44:142-5.

41. Simons FER, Simons KJ, Becker AB, Haydey RP. Pharmacokinetics and antipruritic effects of hydroxysine in children with atopic dermatitis. J Pediatr 1984;104:123-7.
42. Hjorth $\mathrm{N}$. Terfenadine in the treatment of chronic idiopathic urticaria and atopic dermatitis. Cutis 1988;42:29-30.

43. Duherty V, Sylvester DGH, Kennedy CTC, Harvey SG, Calthrop JG, Gibson JR. Treatment of itching in atopic eczema with antihistamines with a low sedative profile. Br Med J 1989;298:96

44. Zuluage de Cadena A, Ochoa de VA, Donado JH, Mejia JI, Chamah H, Motoya de Restrepo F. Comparative study of the effect of the hidroxicina the terfenadina and the astemizol in children with atopic dermatitis: Hospital General de Medellin-Centro de Espechiakistas C. E. S. 1986-1988. CES Med 1989;3:7-13.

45. Monroe EW. Relative efficacy and safety of loratadine, hydroxyzine, and placebo in chronic idiopathic urticaria and atopic dermatitis. Clin Ther 1992;14:17-21.

46. Hannuksela M, Kalimo K, Lammintausta K Mattila T, Turjanmaa K, Varjonen E, et al. Dose ranging study: cetirizine in the treatment of atopic dermatitis in adults. Ann Allergy 1993;70:127-33.

47. Langeland T, Fagertun HE, Larsen S. Therapeutic effect of loratadine on pruritus in patients with atopic dermatitis. A multi-crossover-designed study. Allergy 1994;49:22-6.

48. La Rosa M, Ranno C, Musarra I, Guglielmo F, Corrias A, Bellanti JA. Double-blind study of cetirizine in atopic eczema in children. Ann Allergy 1994;73:117-22

49. Hamada T, Ishii M, Nakagawa K, Kobayashi H, Kitajima J, Chanoki M, et al. Evaluation of the clinical effect of terfenadine in patients with atopic dermatitis. A comparison of strong topical corticosteroid therapy to mild topical corticosteroid combined with terfenadine administration therapy. Skin Res 1996;38:97-103 (in Japanese).

50. Patel P, Gratton D, Eckstein G, Aberer W, Pryzbilla B, Chelly M. A double-blind study of loratadine and cetiridine in atopic dermatitis. J Dematol Treat 1997;8:249-53.

51. Foulds IS, MacKie RM. A double-blind trial of the $\mathrm{H} 2$ receptor antagonist cimetidine, and the $\mathrm{H} 1$ receptor antagonist promethazine hydrochloride in the treatment of atopic dermatitis. Clin Allergy 1981;11:319-23.

52. Frosch PJ, Schwanits HJ, Macher E. A double-blind trial of $\mathrm{H} 1$ and $\mathrm{H} 2$ receptor antagonists in the treatment of atopic dermatitis. Arch Dermatol Res 1984;276:36-40.

53. Savin JA, Dow R, Harlow BJ, Massey H, Yee KF. The effect of a new nonsedative H1-receptor antagonist (LN2974) on the itching and scratching of patients with atopic eczema. Clin Exp Dermatol 1986;11:600-2.

54. Berth-Jones J, Graham-Brown RAC. Failure of terfenadine in relieving the pruritus of atopic dermatitis. Br J Dermatol 1989;121:635-7.

55. Wahlgren CF, Hägermark Ö, Bergström R. The antipruritic effect of a sedative and a non-sedative antihistamine in atopic dermatitis. $\mathrm{Br} J$ Dermatol 1990;122:545-51.

56. Krause L, Shuster S. Mechanism of action of antipruritic drug. $\mathrm{Br} \mathrm{Med} \mathrm{J}$ 1983;287:1199-200

57. Henz BM, Metzenauer P, O'Keefe E, Zuberbier T. Differential effects of new-generation h1-receptor antagonists in pruritic dermatoses. Allergy 1998;53:180-3.

58. Ishibashi $Y$, Ueda H, Niimura M, Harada S, Tamaki K, Imamura S, et al Clinical evaluation of E-0659 in atopic dermatitis in infants and children. Dose-finding multicenter study by the double-blind method. Skin Res 1989:31:458-71(in Japanese).

59. Klein PA, Clark RAF. An evidence-based review of the efficacy of antihistamines in relieving pruritus in atopic dermatitis. Arch Dermatol 1999;135:1522-5.

60. Kawashima M, Tango T, Noguchi T, Inagi M, Nakagawa H, Harada S. Addition of fexofenadine to a topical corticosteroid reduces the pruritus associated with atopic dermatitis in a 1-week randomized, double-blind, placebo-controlled, parallel-group study. Br J Dermatol 2003;148:1212-21.

61. Sowden JM, Berth-Jones J, Ross JS, Montley RJ, Marks R, Finley AY, et al. Double-blind, controlled crossover study of cyclosporin in adults with severe refractory atopic dermatitis. Lancet 1991;338:137-40.

62. Sepp N, Fritsch PO. Can cyclosporin A induce permanent remission of atopic dermatitis? Br J Dermatol 1993;128:213-6.

63. Munro CS, Jevell NJ, Shuster S, Friedmann PS. Maintenance treatment with cyclosporin in atopic dermatitis.Br J Dermatol 1994;130:376-80.

64. Berth-Jones J, Graham-Brown RAC, Marks R, Camp RDR, English JSC, Freeman K, et al. Long-term efficacy and safety of cyclosporin in severe adult atopic dermatitis. Br J Dermatol 1997;136:76-81.

65. Ellis C, Luger T on behalf of the ICCAD II Faculty: Abeck D, Allen R, Graham-Brown RAC, Prost YDE, Eichenfield LF, Ferrandiz C, et al. International Consensus Conference on Atopic Dermatitis II (ICCAD II): Clinical update and current treatment strategies. Br J Dermatol 2003 ; 148(Suppl 63):3-10. 
66. Nakagawa H, Etoh T, Ishibashi Y, Higaki Y, Kawashima M. Torii H, et al Tacrolimus ointment for atopic dermatitis. Lancet 1994;344:883.

67. Aoyama H, Tabata N, Tanaka M, Uesugi Y, Tagami H. Successful treatment of resistant facial lesions of atopic dermatitis with $0.1 \%$ FK506 ointment. Br J Dermatol 1995;133:494-6.

68. Meurer M, Fölster-Holst R, Wozel G, Weidinger G, Jünger M, Bräutigam $\mathrm{M}$, et al. Pimecrolimus cream in the long-term management of atopic dermatitis in adults: a six-month study. Pharmacol Treat 2002;205; 271-7.

69. Kapp A, Rapp K, Bingham A, Fölster-Holst R, Ortonne J-P, Potter PC, et al. Long-term management of atopic dermatitis in infants with topical pimecrolimus, a nonsteroid anti-inflammatory drug. J Allergy Clin Immunol 2002;110:277-84.

70. Japanese FK 506 Ointment Study Group. Clinical guidance for treatment of patients with atopic dermatitis by tacrolimus ointment $0.1 \%$ and 0.03\%. Rinsho Hihu 2003;13:1217-34 (in Japanese)

71. Ishii M, Kobayashi H, Mizuno N. EBM in Dermatological diseases Prog Med 2002;22:2131-5 (in Japanese).

72. Jensen P. Alternative therapy for atopic dermatitis and psoriasis: patientreported motivation, information source and effect. Acta Derm Venereol 1990;70:421-4.

73. Ernst E, Pittler MH, Stevinson C. Complementary/alternative medicine in dermatology: evidence-assessed efficacy of two diseases and two treatments. Am J Clin Dermatol 2002;3:341-8.

74. Simpson EL, Basco M, Hanifin J. A cross-sectional survey of complementary and alternative medicine use in patients with atopic dermatitis Am J Contact Dermat 2003;14:144-7.

75. Takahashi K, Ishii M, Asai Y, Hamada T. Experiences of therapy for skin disease by Japanese herbal medicine. Kampo Med 1981;5:9-11 (in Japanese).

76. Yamamoto I. Clinical dermatology 7, Eczema and dermatitis II, atopic dermatitis. The Kampo 1986;4:2-17 (in Japanese).

77. Ninomiya F. Kampo for adult atopic dermatitis. Gendai Toyo igaku 1988;9:162-5 (in Japanese).

78. Kobayashi H, Ishii M, Tanii T, Kono T, Hamada T. Kampo therapies for atopic dermatitis: The effectiveness of Hochu-ekki-to. Nishinihon Hifu 1989;51:1003-13 (in Japanese).

79. Morohashi M, Takahashi S. Kampo medicine for atopic dermatitis. Allerugi no Rinsho 1989;9:711-4 (in Japanese).

80. Ishii M. Combination therapy with diet and traditional Japanese medicine for intractable adult atopic dermatitis-Interpretation of dietary influence. In Dermatological Oriental Medicine Study Group, editors, State of herb treatments in dermatology 10. Tokyo: Kyowa Kikaku Tsushin, 1999; 35-42 (in Japanese).

81. Kobayashi H, Mizuno N, Teramae H, Kutsuna H, Ueoku S, Onoyama J. Diet and Japanese Herbal Medicine for recalcitrant atopic dermatitis: Efficacy and safety of the treatment. Drug Exp Clin Res in press.

82. Harper JI, Yang S-L, Evans AT, Evans FJ, Phillipson JD. Chinese herbs for eczema. Lancet 1990;335:795.

83. Harper JI. Chinese herbs for eczema. Lancet 1990;336:177.

84. Atherton D, Sheehan M, Rustin MHA, Buckley C, Brostoff J, Taylor N. Chinese herbs for eczema. Lancet 1990;336:1254.

85. Davis I, Pollock HM, Steel. Chinese herbs for eczema. Lancet 1990; 336:177.

86. Graham-Brown R. Toxicity of Chinese herbal remedies. Lancet 1992; 340:673.

87. Perharic-Walton L, Murray V. Toxicity of Chinese herbal remedies Lancet 1992;340:674.

88. Banerjee P, Rustin MHA. Efficacy of a new palatable formulation of Chinese herbal therapy as a treatment of atopic dermatitis. Br J Dermatol 1994;131(Suppl 44):26.

89. Harper J. Traditional Chinese medicine for eczema. Br Med J 1994;308: 489-90.

90. Rustin MHA, Atherton DJ. Chinese herbs and atopic dermatitis. Lancet 1994;343:489.

91. Sheehan MP, Stevens H, Ostlere LS, Atherton DJ, Brostoff J, Rustin MH Follow-up of adult patients with atopic eczema treated with Chinese herbal therapy for 1 year. Clin Exp Dermatol 1995;20:136-40.

92. Ferguson JE, Chalmers RJG, Rowlands DJ. Reversible dilated cardiomyopathy following treatment of atopic eczema with Chinese herbal medicine. Br J Dermatol 1997;136:592-3.
93. Koo J, Arain S. Traditional Chinese medicine for the treatment of dermatologic disorders. Arch Dermatol 1998;134:1388-93.

94. Worm M, Henz BM. Novel unconventional therapeutic approaches to atopic eczema. Dermatology 2000;201:191-5.

95. Yuan R, Yuan L. Traditional Chinese medicine: an approach to scientific proof and clinical validation. Pharm Therap 2000;86:191-8.

96. Koo J, Desal R. Traditional Chinese medicine in dermatology. Dermatol Ther 2003;16:98-105.

97. Armstrong NC, Ernst E. The treatment of eczema with Chinese herbs: a systemic review of randomized clinical trials. Br J Clin Pharmacol 1999;48:262-4.

98. Sheehan MP, Rustin MHA, Atherton DJ, Buckley C, Harris DJ, Brostoff $\mathrm{J}$, et al. Efficacy of traditional Chinese herbal therapy in adult atopic dermatitis. Lancet 1992;340:13-7.

99. Sheehan MP, Atherton DJ. A controlled trial of traditional Chinese medicine plants in widespread non-exudative atopic eczema. $\mathrm{Br} J$ Dermatol 1992;126:483-8.

100. Sheehan MP, Atherton DJ. One-year follow up of children treated with Chinese medicinal herbs for atopic eczema. Br J Dermatol 1994;130: 488-93.

101. Fung AYP, Look PCN, Chong L-Y, But PPH, Wong E. A controlled tria of traditional Chinese herbal medicine in Chinese patients with recalcitrant atopic dermatitis. Int J Dermatol 1999;38:387-92.

102. Latchman Y, Whitte B, Rustin M, Atherton DJ, Brostoff J. The efficacy of traditional Chinese herbal therapy in atopic eczema. Int Arch Allergy Immunol 1994;104:222-6.

103. Latchman Y, Bungy GA, Atherton DJ, Rustin MHA, Brostoff J. Efficacy of traditional Chinese herbal therapy in vitro. A model system for atopic eczema: inhibition of CD23 expression on blood monosytes. $\mathrm{Br} \mathrm{J}$ Dermatol 1995;132:592-8.

104. Latchman Y, Banerjee P, Poulter LW, Rustin M, Brostoff J. Association of immunological changes with clinical efficacy in atopic eczema patients treated with traditional Chinese herbal therapy (Zemaphyte ${ }^{\circledR}$ ). Int Arch allergy Immunol 1996;109:243-9.

105. Xu XJ, Banerjee P, Rustin MH, Poulter LW. Modulation by Chinese herbal therapy of immune mechanisms in the skin of patients with atopic eczema. Br J Dermatol 1997;136:54-9.

106. Atherton DJ, Sheehan MP, Rustin MHA, Whitte B, Guy G. Treatment of atopic eczema with traditional Chinese medicinal plants. Ped Dermatol 1992:9:373-5.

107. Latchman YE, Xu XJ, Poulter LW, Rustin MHA, Atherton DJ, Brostoff J. Chinese medical herbs in the treatment of atopic dermatitis. ACI international 2002;14:4-9.

108. Kobayashi H, Mizuno N, Kutsuna H, Teramae H, Ueoku S, Onoyama J. Hochu-ekki-to suppresses development of dermatitis and elevation of serum IgE level in NC/Nga mice. Drug Exp Clin Res 2003;29:81-4.

109. Soronsen HT, Mellemkjaer L, Nielsen G, Baron JA, Olsen JH, Karagas MH Skin cancers and non-Hodgkin lymphoma among users of systemic corticosteroids: A population based cohort study J Natl Cancer Inst 2004;96:709-11.

110. Guyatt G, Sackett D, Taylor WD, Chong J, Roberts R, Pughsley S Determining optimal therapy-randomized trials in individual patients. N Engl J Med 1986;314:689-92.

111. Guyatt G, Sackett D, Adachi J, Roberts R, Chong J, Rosenbloom D, et al A clinician's guide for conducting randomized trials in individual patients. CMAJ 1988;139:497-503.

112. Nuovo J, Ellsworth AJ, Larson EB. Treatment of atopic dermatitis with antihistamines: lessons from a single patient, randomized clinical trial. J Am Board Fam Pract 1992;5:137-42.

113. Sackett DL, Richardson WS, Rosenberg W, Haynes RB, editors N-of-1 trials: selecting the optimal treatment with a randomized trial in an individual patient. In Evidence-Based Medicine. How to Practice and Teach EBM, 2nd Edition. New York and Edinburgh: Churchill Livingstone, 1997;173-5.

114. Price JD, Evans JG. N-of-1 randomized controlled trials ('N-of-1 trials') singularly useful in geriatric medicine. Age Aging 2002;31:227-32.

115. Terasawa K. High quality evidence in Kampo. In Terasawa K, Kita T, editors, EBM Kampo, Tokyo: Ishiyaku Publisher Inc., 2003; 5-8.

116. Terasawa K. How to elaborate EBM in Kampo Medicine. Kampo Med 2004;55:1-12. 


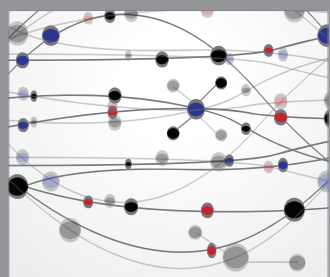

The Scientific World Journal
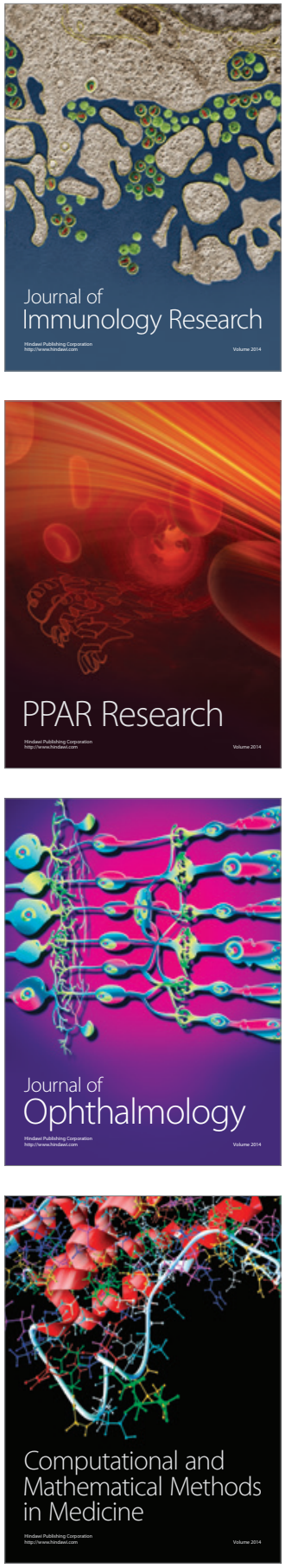

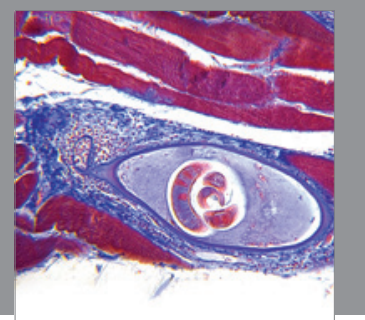

Gastroenterology

Research and Practice
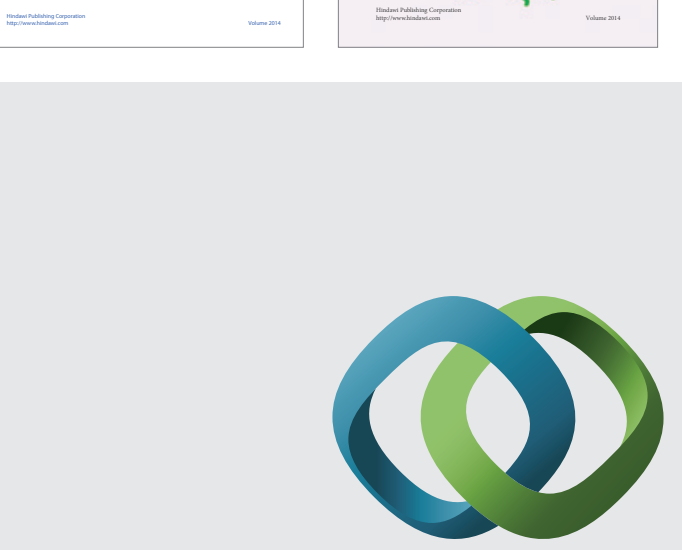

\section{Hindawi}

Submit your manuscripts at

http://www.hindawi.com
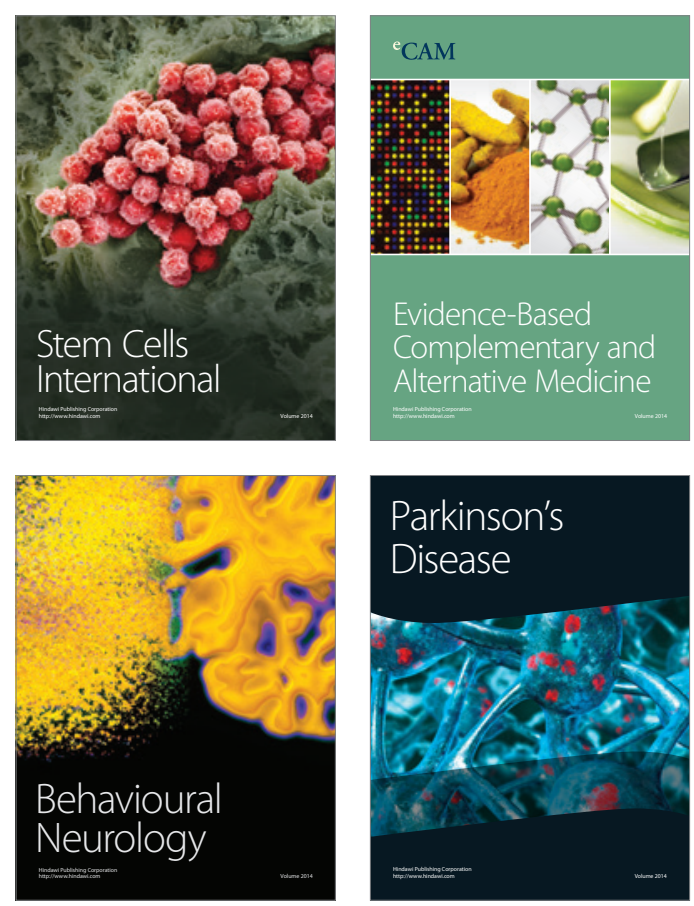

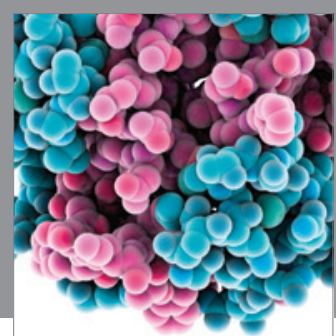

Journal of
Diabetes Research

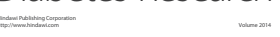

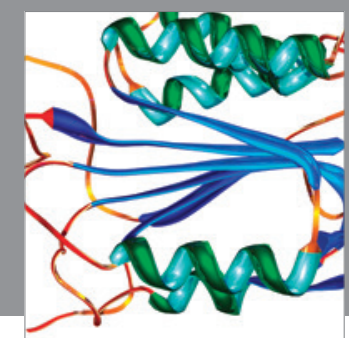

Disease Markers
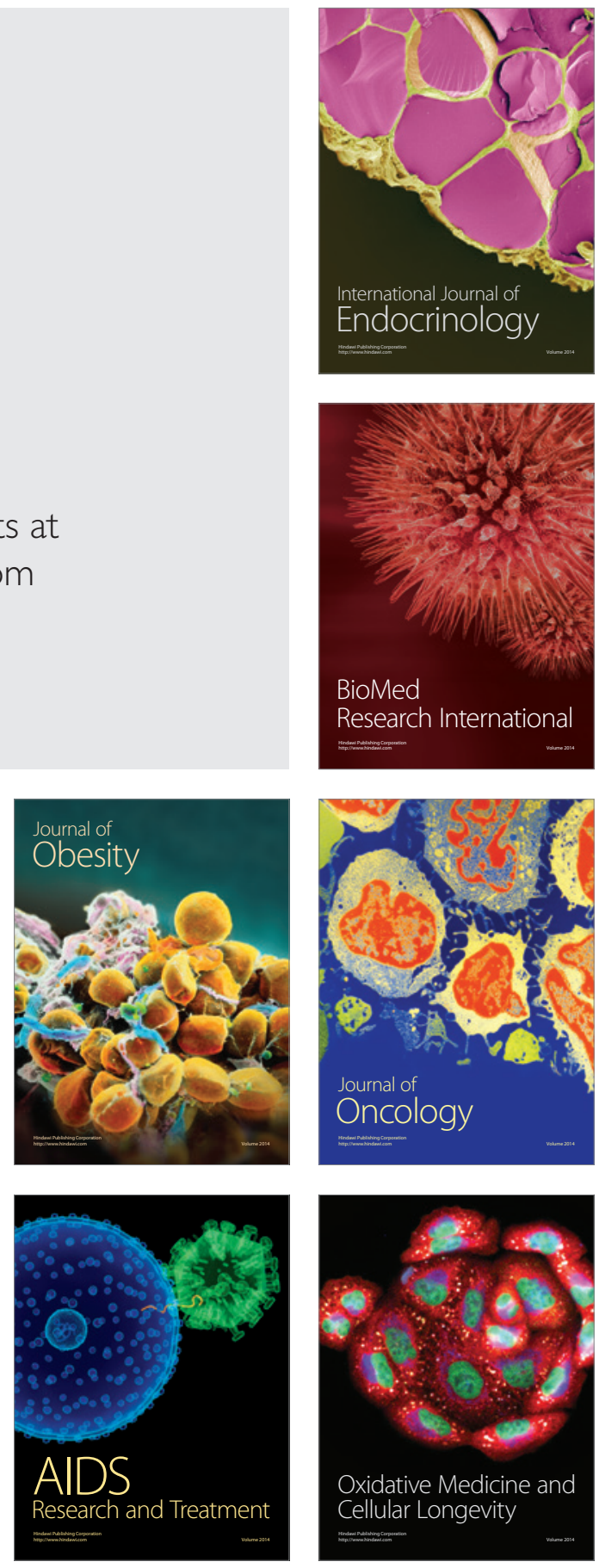